\title{
Efeito de Raça e Heterose para Características de Carcaça de Novilhos da Primeira Geração de Cruzamento entre Charolês e Nelore
}

\author{
Fabiano Nunes Vaz'1, João Restle ${ }^{2}$
}

\begin{abstract}
RESUMO - Foram estudadas as características de carcaça de novilhos gerados por dois sistemas de acasalamento: puros (P) e cruzados $\mathrm{F}_{1}$. O sistema de acasalamento $\mathrm{P}$ foi constituído por animais das raças Charolês $(\mathrm{C})$ e Nelore $(\mathrm{N})$ e o $\mathrm{F}_{1}$, por animais $1 / 2 \mathrm{C}+1 / 2 \mathrm{~N}$ e $1 / 2 \mathrm{~N}+1 / 2 \mathrm{C}$. Foram utilizados 463 animais, nascidos desde 1984 até 1996 . Os animais cruzados foram superiores aos puros em peso de abate, peso de carcaça, conformação, comprimento de carcaça, espessura de coxão, perímetro de braço, porcentagem de costilhar, espessura de gordura e área de Longissimus, sendo os níveis de heterose, em porcentagem, de 10,$7 ; 11,6 ; 3,8 ; 2,9 ; 2,5 ; 2,8 ; 3,1 ; 14,2 ;$ e 8,0, respectivamente. Os animais puros foram superiores aos cruzados em porcentagem de serrote e de osso na carcaça. Na comparação entre os novilhos $\mathrm{P}$, os $\mathrm{C}$ mostraram melhores pesos de abate e carcaça, conformação, comprimento de carcaça, espessura de coxão, percentagem de costilhar e de serrote e área de Longissimus, mas foram inferiores aos $\mathrm{N}$ em rendimento de carcaça, comprimento de perna, comprimento de braço, porcentagem de dianteiro e espessura de gordura subcutânea. O cruzamento entre C e N propiciou heterose positiva para características de carcaça muito importantes sob o ponto de vista comercial.
\end{abstract}

Palavras-chave: Bos indicus, Bos taurus, conformação, espessura de gordura, rendimento de carcaça

\section{Breed and Heterosis Effects on Carcass Traits of Steers from the First Crossbreeding Generation Between Charolais and Nellore}

\begin{abstract}
Carcass traits of steers from two breeding systems, straightbreds ( $\mathrm{S}$ ) and $\mathrm{F}_{1}$ crossbreds were studied. The $\mathrm{S}$ breeding system included the Charolais $(\mathrm{C})$ and the Nellore $(\mathrm{N})$ breeds and the $\mathrm{F}_{1}$ included $1 / 2 \mathrm{C}+1 / 2 \mathrm{~N}$ and $1 / 2 \mathrm{~N}+1 / 2 \mathrm{C}$ crosses. A total of 463 steers, born from 1984 to 1996 were used. The crossbred steers were superior to the purebreds in slaughter weight, carcass weight, conformation, carcass length, cushion thickness, arm perimeter, sidecut percentage, fat thickness and Longissimus muscle area, and the heterosis levels, in percentage, were 10.7, 11.6, 3.8, 2.9, 2.5, 2.8, 3.1, 14.2 and 8.0, respectively. Straightbred animals were superior than the $\mathrm{F}_{1}$ in sawcut percentage and bone percentage. Between the straightbreds the $\mathrm{C}$ group showed higher slaughter weight, carcass weight, conformation, carcass length, cushion thickness, sidecut percentage, sawcut percentage and Longissimus muscle area, but they were inferior than the $\mathrm{N}$ group in dressing percentage, leg length, arm length, forequarter percentage and subcutaneous fat thickness. Crossbreeding between $\mathrm{C}$ and $\mathrm{N}$ resulted on positive heterosis for important commercial traits.
\end{abstract}

Key Words: Bos indicus, Bos taurus, conformation, dressing percentage, fat thickness

\section{Introdução}

No grupo das raças Bos taurus, a Charolesa é a raça de grande porte mais criada no Rio Grande do Sul, devido às suas características de velocidade de crescimento e alto peso ao abate. Já a Nelore (Bos indicus) é a raça bovina mais criada no Brasil. Nos últimos anos, é grande o número de produtores do centro do país que estão introduzindo raças européias no rebanho Nelore e, na região Sul, é grande a aceitação das raças zebuínas para o cruzamento com as européias. Segundo KOGER (1980), em ambos os casos, os produtores buscam, principalmente, explorar o alto nível de heterose originária da habilidade de combinação existente entre os grupos raciais Bos taurus e Bos indicus.
Apesar de os trabalhos sobre cruzamento de bovinos de corte demandarem grande infra-estrutura e tempo, é a partir destes experimentos que importantes conclusões estão tornando mais claros os benefícios que os cruzamentos em bovinos de corte podem trazer ao produtor (RESTLE e VAZ, 1999), comprovando a importância do melhoramento genético (FRIES, 1999) na produtividade de um rebanho.

O objetivo deste trabalho foi estudar, na primeira geração de cruzamento entre as raças Charolesa e Nelore, os efeitos da raça e da heterozigose presentes nos animais $\mathrm{F}_{1}$ sobre características de carcaça de novilhos abatidos aos dois anos de idade. 


\section{Material e Métodos}

Os estudos de campo deste trabalho, que acompanhou o desenvolvimento dos novilhos desde o nascimento até o abate, foram realizados na área experimental do Setor de Bovinocultura de Corte do Departamento de Zootecnia da Universidade Federal de Santa Maria - RS (UFSM).

Foram utilizados os dados referentes a 188 novilhos da raça Charolesa (C), 125 novilhos da raça Nelore (N), 72 novilhos $1 / 2 \mathrm{C}+1 / 2 \mathrm{~N}$ e 78 novilhos $1 / 2 \mathrm{~N}+$ 1/2 C, nascidos de 1984 a 1996, totalizando 463 novilhos. Por ocasião do início do projeto, em 1984, foram utilizadas fêmeas $\mathrm{C}$ e $\mathrm{N}$ aptas à reprodução, oriundas de diferentes rebanhos da região. Essas fêmeas foram divididas aleatoriamente em dois grupos e geraram produtos puros e cruzados $\left(\mathrm{F}_{1}\right)$.

Em cada ano, foi utilizado sêmen de seis touros de cada raça $(\mathrm{C}$ e $\mathrm{N})$, sendo que esse sêmen foi adquirido junto às casas comerciais especializadas, procurando-se sempre touros de qualidade média dentro da sua raça. Utilizou-se sêmen dos touros no mínimo por dois anos consecutivos. No momento da inseminação artificial, após a identificação da raça que deveria ser utilizada em determinado ventre, a escolha do sêmen foi aleatória. Quatro touros de cada raça foram utilizados para o repasse em monta a campo. Os touros escolhidos foram, também, de qualidade média, trazidos de cabanhas tradicionais que se dispuseram a emprestar seus reprodutores para a Universidade. Os touros $\mathrm{C}$ que geraram os novilhos $\mathrm{C}$ foram os mesmos que geraram produtos $1 / 2 \mathrm{C}+1 / 2 \mathrm{~N}$, assim como os touros $\mathrm{N}$ que geraram novilhos $\mathrm{N}$ foram os mesmos que produziram novilhos $1 / 2 \mathrm{~N}+1 / 2 \mathrm{C}$.

A recria e a terminação dos animais foram as mesmas para todos os grupos genéticos e variaram de ano para ano, podendo ter sido em confinamento ou em pastagem cultivada de inverno, com a utilização ou não de suplemento energético. A castração dos animais ocorreu quando estes apresentavam, em média, sete meses de idade.

Os animais foram abatidos, em média, aos 24 meses de idade. O peso de fazenda foi tomado antes do embarque para o abatedouro, obedecendo jejum de sólidos de 12 horas. Os abates seguiram o fluxo normal do frigorífico onde estes ocorriam. Após o abate, a carcaça do animal foi identificada antes de entrar para a câmara de resfriamento do estabelecimento. Após 24 horas de resfriamento a $2^{\circ} \mathrm{C}$, mediram-se o peso de carcaça fria, a conformação, a maturidade fisiológica da carcaça e as medidas de desenvolvimento da carcaça, seguindo-se a metodologia sugerida por MULLER (1987).

As medidas da porcentagem de dianteiro, costilhar e serrote foram realizadas pela separação destes cortes, pesagem e posterior cálculo da porcentagem destes em relação ao peso de meia carcaça. A área de longissimus foi medida na altura da $12^{\mathrm{a}}$ costela, na qual se mensurou a área desse músculo realizando-se um corte perpendicular ao comprimento do mesmo. Nesse mesmo corte foi medida a espessura de gordura subcutânea. Já os pesos de músculo, gordura e osso foram obtidos por meio da multiplicação do peso de carcaça fria pelas respectivas percentagens de músculo, gordura e osso, as quais foram determinadas pela metodologia sugerida por HANKINS e HOWE (1946).

O delineamento experimental foi inteiramente casualizado, com número diferente de observações por tratamento. Todas as características de interesse foram analisadas utilizando-se o seguinte modelo estatístico:

$\mathrm{Y}_{\mathrm{ijklm}}=\mu+\mathrm{GC}_{\mathrm{i}}+\mathrm{IV}_{\mathrm{j}}+\mathrm{SA}_{\mathrm{k}}+\mathrm{R}_{\mathrm{l:k}}+\mathrm{bIA}_{\mathrm{m}}+\mathrm{e}_{\mathrm{ijklm}}$ em que $Y_{i j k l m}$ representa a observação realizada no n-ésimo animal, pertencente ao i-ésimo grupo de contemporâneos, ao k-ésimo sistema de acasalamento e a l-ésima composição racial, cuja mãe ao parto possui a j-ésima idade; $\mu$, a média geral da característica; $\mathrm{GC}_{\mathrm{i}}$, o efeito do i-ésimo grupo de contemporâneos; $\mathrm{IV}_{\mathrm{j}}$, o efeito da j-ésima idade da vaca; $\mathrm{SA}_{\mathrm{k}}$, o efeito do k-ésimo sistema de acasalamento; $\mathrm{R}_{\mathrm{l}: \mathrm{k}}$, $\mathrm{o}$ efeito da l-ésima composição racial, dentro do k-ésimo sistema de acasalamento; b, coeficiente de regressão; $\mathrm{IA}_{\mathrm{m}}$, a idade em dias ao abate do m-ésimo animal; $\mathrm{e}_{\mathrm{ijklm}}$, o efeito residual, associado a observação realizada no m-ésimo animal.

Em análises preliminares, testaram-se o efeito quadrático da IA e o efeito do peso do animal aos doze meses. Como esses efeitos não foram significativos, eles foram removidos do modelo estatístico final. Os grupos de contemporâneos foram formados por animais nascidos no mesmo ano e abatidos na mesma data. Portanto, quando dentro do mesmo ano ocorriam abates em diferentes datas, eram formados grupos de contemporâneos diferentes, em função de que determinado lote permanecia por mais tempo em terminação. Entretanto, em cada grupo de contemporâneos sempre havia animais de todas as composições raciais que já haviam sido geradas até aquele ano.

Na comparação entre SA, foi utilizado o teste " $t$ " para realizar o contraste entre as médias. As médias para cada característica, extraídas da comparação entre os SA (puros e cruzados $\mathrm{F}_{1}$ ), foram utilizadas 
para calcular a heterose pela seguinte fórmula:

$\%$ Heterose $=\left[\mathrm{MCF}_{1}-\mathrm{MDEF}\right] \mathrm{X} 100 / \mathrm{MDEF}$ em que $\mathrm{MCF}_{1}$ é média estimada dos animais cruzados $\mathrm{F}_{1}$ e MDEF, média estimada dos animais puros.

As comparações das composições raciais foram realizadas dentro dos SA. Os seguintes contrastes foram estudados:

C versus $N$ : permite uma estimativa da diferença aditiva entre as raças $\mathrm{C}$ e $\mathrm{N}$.

$1 / 2 C+1 / 2 N$ versus $1 / 2 N+1 / 2 C$ : estima o efeito recíproco das raças, decorrente principalmente do possível efeito materno. O programa estatístico utilizado foi o SAS (1990).

\section{Resultados e Discussão}

Na Tabela 1 são apresentadas as médias estimadas referentes ao peso de abate, peso de carcaça fria, rendimento de carcaça fria e maturidade fisiológica da carcaça dos novilhos das raças Charolesa (C), Nelore (N) e cruzados $1 / 2 \mathrm{C}+1 / 2 \mathrm{~N}$ e $1 / 2 \mathrm{~N}+1 / 2 \mathrm{C}$, assim como as médias estimadas de cada $\mathrm{SA}$ e a heterose na $\mathrm{F}_{1}$.

Observa-se na Tabela 1 que, na comparação entre os $\mathrm{SA}$, os animais cruzados apresentaram maiores peso de abate e peso de carcaça fria que os puros. Observa-se, na mesma tabela, que os níveis de heterose no $\mathrm{F}_{1}$ foram de $10,7 \%$ para a característica peso de abate e $11,6 \%$ para peso de carcaça fria. Esses valores de heterose estão de acordo com os trabalhos brasileiros conduzidos com o intuito de avaliar características de desenvolvimento dos animais (ALENCAR et al., 1998; PEROTTO et al., 1998).

Ainda na Tabela 1, observa-se que o rendimento de carcaça não diferiu entre os animais puros e cruzados $\mathrm{F}_{1}$. O baixo valor da heterose $(0,7 \%)$ está de acordo com os resultados de LONG (1980), que comenta que níveis de heterose para rendimento oscilam ao redor de $1 \%$.

Na Tabela 1, observa-se que, na comparação entre SA, a conformação foi melhor $(\mathrm{P}<0,05)$ nos novilhos cruzados, sendo a heterose de $3,8 \%$. Com relação à maturidade fisiológica, verifica-se que os SA não mostraram diferença entre si, o que também foi observado entre as composições raciais dentro de cada $\mathrm{SA}(\mathrm{P}>0,05)$. O nível de heterose negativo e não significativo $(\mathrm{P}>0,05)$ encontrado nesta característica (-0,8\%) também é relatado por BAKER et al. (1984), no cruzamento entre Brahman, duas raças de corte britânicas e duas raças leiteiras, quando a heterose no $\mathrm{F}_{1}$ foi de $-0,7 \%$.

Na comparação entre as raças definidas, os animais $\mathrm{C}$ apresentaram maior peso de abate que os $\mathrm{N}$. A diferença de $83 \mathrm{~kg}$ verificada entre os dois grupos é reflexo do maior porte do $\mathrm{C}$, em relação ao $\mathrm{N}$, e à maior seleção que as raças européias destinadas ao

Tabela 1 - Médias estimadas e heterose para peso de abate, peso de carcaça fria, rendimento de carcaça fria, conformação e maturidade fisiológica da carcaça de novilhos oriundos do cruzamento entre as raças Charolesa $(C)$ e Nelore $(N)$

Table 1 - Least square means and heterosis for slaughter weight, cold carcass weight, dressing percentage, conformation and physiologic maturity of carcasses of steers from crossbreeding between Charolais $(C)$ and Nellore $(N)$

\begin{tabular}{|c|c|c|c|c|c|}
\hline $\begin{array}{l}\text { Composição } \\
\text { racial } \\
\text { Breed composition }\end{array}$ & $\begin{array}{l}\text { Peso de } \\
\text { abate, kg } \\
\text { Slaughter } \\
\text { weight, kg }\end{array}$ & $\begin{array}{c}\text { Peso de } \\
\text { carcaça, kg } \\
\text { Carcass } \\
\text { weight, } k g\end{array}$ & $\begin{array}{c}\text { Rendimento de } \\
\text { carcaça, \% } \\
\text { Dressing } \\
\text { percentage }\end{array}$ & $\begin{array}{l}\text { Conformação, } \\
\text { pontos } \\
\text { Conformation, } \\
\text { score }\end{array}$ & $\begin{array}{l}\text { Maturidade, } \\
\text { pontos } \\
\text { Phys. maturity, } \\
\text { score }\end{array}$ \\
\hline $\mathrm{C}$ & $462 \mathrm{a}^{2}$ & $241 \mathrm{a}$ & $52,2 \mathrm{~b}$ & $11,6 \mathrm{a}$ & 13,2 \\
\hline $\mathrm{N}$ & $379 b$ & $208 b$ & $54,8 \mathrm{a}$ & $9,4 \mathrm{~b}$ & 13,2 \\
\hline Média puros & $420 \mathrm{~B}^{1}$ & $224 \mathrm{~B}$ & 53,5 & $10,5 \mathrm{~B}$ & 13,2 \\
\hline \multicolumn{6}{|l|}{ Straightbreds mean } \\
\hline $1 / 2 \mathrm{C}+1 / 2 \mathrm{~N}$ & 469 & 250 & 53,4 & 10,8 & 13,0 \\
\hline $1 / 2 \mathrm{~N}+1 / 2 \mathrm{C}$ & 461 & 251 & 54,4 & 10,9 & 13,1 \\
\hline $\begin{array}{l}\text { Média } \mathrm{F}_{1} \\
F_{1} \text { mean }\end{array}$ & $465 \mathrm{~A}$ & $250 \mathrm{~A}$ & 53,9 & $10,9 \mathrm{~A}$ & 13,1 \\
\hline $\begin{array}{l}\text { Heterose, } \% \\
\text { Heterosis, \% }\end{array}$ & 10,7 & 11,6 & $0,7\left(\mathrm{NS}^{3}\right)$ & 3,8 & $-0,8(\mathrm{NS})$ \\
\hline
\end{tabular}

${ }^{1} \mathrm{~A}, \mathrm{~B}$, na coluna, na comparação entre puros e $F_{1}$ diferem pelo teste "t" $(P<0,05)$.

2 a,b, na coluna, na comparação entre $\mathrm{C}$ e $\mathrm{N}$, diferem pelo teste "t" $(\mathrm{P}<0,05)$.

3 Indica heterose não significativa $(P>0,05)$.

${ }_{1} A, B$, in the column, for comparison between straigthbreds and $F_{1}$, differ by $t$ test $(P<.05)$.

$2 a, b$, in the column, for comparison between $C$ and $N$, differ by $t$ test $\left(P_{<} .05\right)$.

${ }^{3}$ Non significant heterosis $(P>.05)$. 
corte sofreram ao longo dos anos. Vários autores têm comentado o grande desenvolvimento que a raça $\mathrm{C}$ apresenta, sendo indicada para aumentar o peso de abate dos animais cruzados (URICK et al., 1989; DeROUEN et al., 1992b; PEROBELLI et al., 1995; RESTLE et al., 1995b; WHEELER et al., 1996; FLORES, 1997).

Assim como o peso de abate, o peso de carcaça também foi maior nos animais $\mathrm{C}$, embora o rendimento dos novilhos $\mathrm{N}$ tenha sido superior $(54,8 v s .52,2 \%$; $\mathrm{P}<0,05)$. Vários trabalhos têm demonstrado maior rendimento de carcaça em animais zebuínos em comparação com europeus (PEROBELLI et al., 1995; RESTLE et al., 1995a; MOLETTA e RESTLE, 1996; WHEELER et al., 1996; FEIJÓ et al., 1997; RESTLE et al., 1999). Esse maior rendimento é reflexo do menor peso relativo de patas, cabeça, couro e, principalmente, trato digestivo dos zebuínos (GALVÃO, 1991). O trato digestivo reduzido é reflexo da maior adaptabilidade das raças zebuínas às condições adversas nas quais evoluíram (Ásia e África); também a menor espessura do couro e maior superfície relativa do corpo são características de adaptação dos genótipos zebuínos aos climas mais quentes (PRESTON e WILLIS, 1970).

Na comparação entre os animais $\mathrm{F}_{1}$, observa-se que, embora a diferença não tenha sido significativa $(\mathrm{P}>0,05)$ no peso de abate entre os grupos $1 / 2 \mathrm{C}+$ $1 / 2 \mathrm{~N}$ e $1 / 2 \mathrm{~N}+1 / 2 \mathrm{C}$, houve diferença numérica de
$8 \mathrm{~kg}$ a favor dos primeiros, no entanto, a diferença numérica $(\mathrm{P}>0,05)$ observada no rendimento de carcaça a favor dos $1 / 2 \mathrm{~N}+1 / 2 \mathrm{C}$ fez com que o peso de carcaça fosse praticamente o mesmo entre as composições raciais, ou seja, $250 \mathrm{~kg}$ nos novilhos $1 / 2 \mathrm{C}+1 / 2 \mathrm{~N}$ e $251 \mathrm{~kg}$ nos novilhos $1 / 2 \mathrm{~N}+1 / 2 \mathrm{C}$. Analisando o rendimento de carcaça, JOHNSTON et al. (1992) observaram que as cruzas recíprocas de Devon e Hereford não diferiram nessa característica, sendo observados valores de 50,96\% para os $1 / 2$ Devon $+1 / 2$ Hereford e $51,05 \%$ para os $1 / 2$ Hereford + 1/2 Devon.

Observa-se que os animais $\mathrm{C}$ foram superiores $(\mathrm{P}<0,05)$ em conformação da carcaça. Estudando as vacas de descarte pertencentes a este projeto, PEROBELLI et al. (1995) citam melhor conformação para vacas $\mathrm{C}$. A melhor conformação de carcaça dos animais é reflexo do maior desenvolvimento muscular deste genótipo.

Na Tabela 2 são apresentados os resultados referentes às medidas de desenvolvimento da carcaça dos novilhos. Observa-se que os novilhos $F_{1}$ foram superiores aos puros em comprimento de carcaça e de perna, perímetro e comprimento de braço $(\mathrm{P}<0,05)$, seguindo a tendência do peso de carcaça. Embora sejam poucos os trabalhos que medem as características de desenvolvimento da carcaça, ARTHUR et al. (1989) verificaram heterose para comprimento de carcaça semelhante $(2,8 \%)$ ao valor observado no presente trabalho $(2,90 \%)$.

Tabela 2 - Médias estimadas e heterose para medidas de desenvolvimento da carcaça de novilhos oriundos do cruzamento entre Charolês $(\mathrm{C})$ e Nelore $(\mathrm{N})$

Table 2 - Least square means and heterosis for development measurements of carcass of steers from crossbreeding between Charolais (C) and Nellore $(\mathrm{N})$

\begin{tabular}{lccccc}
\hline $\begin{array}{l}\text { Composição } \\
\text { racial } \\
\text { Breed composition }\end{array}$ & $\begin{array}{c}\text { Compr. de } \\
\text { carcaça, cm } \\
\text { Carcass } \\
\text { length, } \mathrm{cm}\end{array}$ & $\begin{array}{c}\text { Compr. de } \\
\text { perna, cm } \\
\text { Leglength, } \\
\text { cm }\end{array}$ & $\begin{array}{c}\text { Espess. de } \\
\text { coxão, cm } \\
\text { Cushion } \\
\text { thickness, cm }\end{array}$ & $\begin{array}{c}\text { Compr. de } \\
\text { braço, cm } \\
\text { Arm length, } \\
\text { cm }\end{array}$ & $\begin{array}{c}\text { Perím. de } \\
\text { braço, cm } \\
\text { Arm perimeter, } \\
\text { cm }\end{array}$ \\
\hline $\mathrm{C}$ & $125,3 \mathrm{a}^{2}$ & $69,9 \mathrm{~b}$ & $26,0 \mathrm{a}$ & $39,4 \mathrm{~b}$ & $37,0 \mathrm{a}$ \\
$\mathrm{N}$ & $116,2 \mathrm{~b}$ & $73,7 \mathrm{a}$ & $23,6 \mathrm{~b}$ & $40,8 \mathrm{a}$ & $33,7 \mathrm{~b}$ \\
Média puros & $120,8 \mathrm{~B}^{1}$ & $71,8 \mathrm{~B}$ & 24,8 & $40,1 \mathrm{~B}$ & $35,4 \mathrm{~B}$ \\
Straightbreds mean & 123,9 & 74,1 & 25,4 & 41,4 & 36,1 \\
$1 / 2 \mathrm{C}+1 / 2 \mathrm{~N}$ & 124,8 & 73,0 & 25,5 & 41,0 & 36,7 \\
$1 / 2 \mathrm{~N}+1 / 2 \mathrm{C}$ & $124,3 \mathrm{~A}$ & $73,6 \mathrm{~A}$ & 25,4 & $41,2 \mathrm{~A}$ & $36,4 \mathrm{~A}$ \\
Média F & 2,9 & 2,5 & $2,4\left(\mathrm{NS}^{3}\right)$ & 2,7 & 2,8 \\
$F_{1}$ mean & & & & & \\
Heterose, $\%$ & & & & &
\end{tabular}

\footnotetext{
${ }_{1} \mathrm{~A}, \mathrm{~B}$, na coluna, na comparação entre puros e $\mathrm{F}_{1}$ diferem pelo teste "t" $(\mathrm{P}<0,05)$.

$2 a, b$, na coluna, na comparação entre $C$ e $N$, diferem pelo teste "t" $(P<0,05)$.

3 Indica heterose não-significativa $(P>0,05)$.

${ }^{1} A, B$, in the column, for comparision between straigthbreds and $F_{1}$, differ by $t$ test $(P<.05)$.

$2 a, b$, in the column, for comparison between $C$ and $N$, differ by $t$ test $(P<.05)$.

${ }^{3}$ Non signifficant heterosis $(P>.05)$.
} 
$\mathrm{Na}$ comparação dentro dos SA, observa-se que os animais $\mathrm{C}$ apresentaram maior comprimento de carcaça, espessura de coxão e perímetro de braço, enquanto os novilhos $\mathrm{N}$ mostraram pernas e braços mais longos. Estudando animais N e 1/2 Simental + 1/2 N, FEIJÓ et al. (1997) verificaram que a carcaça foi mais curta nos animais N. Avaliando as carcaças de genótipos N x Hereford, RESTLE et al. (1999) verificaram que o incremento de genes $\mathrm{N}$ no cruzamento aumentou o comprimento dos membros e diminuiu o comprimento de carcaça, citando as diferenças morfológicas entre as raças Bos taurus e Bos indicus e o efeito aditivo das duas raças como responsáveis pela variação. Entre os animais $F_{1}$, não foi observada diferença significativa em nenhuma das cinco variáveis que medem o desenvolvimento da carcaça.

Na Tabela 3 são apresentados os resultados referentes à porcentagem dos cortes comerciais, espessura de gordura subcutânea e área de Longissimus na carcaça dos novilhos. Os resultados mostram maior porcentagem de serrote dos puros em contraste com a maior percentagem de costilhar dos novilhos $\mathrm{F}_{1}(\mathrm{P}<0,05)$, sendo a heterose para essa última característica de $3,1 \%$. Na comparação entre animais $\mathrm{N}$ e Holandês e os produtos do cruzamento $\left(\mathrm{F}_{1}\right)$, observou-se $4,0 \%$ de heterose para a porcentagem de costilhar na $F_{1}$ (GONÇALVES, 1988).
Nas vacas de descarte do mesmo projeto, também foi observada maior porcentagem de serrote para a raça $\mathrm{C}$, no entanto, o resultado foi inverso para porcentagem de costilhar, ou seja, este foi maior na raça $N$, não havendo diferença na percentagem de dianteiro (PEROBELLI et al., 1995). A maior porcentagem de costilhar verificada nas vacas $\mathrm{N}$ pode ser resultado do maior grau de acabamento que estas apresentavam $(5,84 \mathrm{~mm})$, se comparado com os novilhos $\mathrm{N}$ do presente trabalho $(3,77 \mathrm{~mm})$, uma diferença de 2,07 mm, e à menor cobertura de gordura das vacas $\mathrm{C}$, que foi de $1,54 \mathrm{~mm}$, enquanto os novilhos $\mathrm{C}$ apresentaram 2,30 $\mathrm{mm}$. Esta justificativa é melhor aceita avaliando-se os resultados de RESTLE et al. (1996, 1997a), que, ao estudarem diferentes pesos de abate em novilhos $\mathrm{C}$, observaram que animais com 2,4 mm de acabamento renderam $13,2 \%$ de costilhar, novilhos com $2,6 \mathrm{~mm}$ renderam $13,4 \%$, e quando o acabamento passou para $5,4 \mathrm{~mm}$, a percentagem de costilhar passou para $15,7 \%$.

Estudando-se os cortes comerciais dentro do SA $\mathrm{F}_{1}$, observa-se que os novilhos $1 / 2 \mathrm{C}+1 / 2 \mathrm{~N}$ foram estatisticamente $(\mathrm{P}>0,05)$ superiores aos $1 / 2 \mathrm{~N}+1 / 2 \mathrm{C}$ na porcentagem de dianteiro, sendo as médias estimadas de 37,9 e $37,3 \%$. Ao contrário do que foi comentado para a diferença no rendimento de carcaça desses dois genótipos, não se espera que as diferen-

Tabela 3 - Médias estimadas e heterose para porcentagem dos cortes comerciais, espessura de gordura e área de Longissimus de novilhos oriundos do cruzamento entre Charolês $(\mathrm{C})$ e Nelore $(\mathrm{N})$

Table 3 - Least square means and heterosis for commercial cuts percentage, fat thickness and Longissimus muscle area of steers from crossbreeding between Charolais (C) and Nellore $(N)$

\begin{tabular}{|c|c|c|c|c|c|}
\hline $\begin{array}{l}\text { Composição } \\
\text { racial } \\
\text { Breed composition }\end{array}$ & $\begin{array}{c}\text { Dianteiro, } \\
\% \\
\text { Forequarter, } \\
\% \\
\end{array}$ & $\begin{array}{l}\text { Costilhar, } \\
\% \\
\text { Sidecut, } \\
\% \\
\end{array}$ & $\begin{array}{c}\text { Serrote, } \\
\% \\
\text { Sawcut, } \\
\%\end{array}$ & $\begin{array}{c}\text { Gordura, } \\
\text { mm } \\
\text { Fat thickness, } \\
\text { mm }\end{array}$ & $\begin{array}{c}\text { Área de Longissumus } \\
\mathrm{cm}^{2} \\
\text { Longissimus area, } \\
\mathrm{cm}^{2}\end{array}$ \\
\hline $\mathrm{C}$ & $37,2 b^{2}$ & $13,0 \mathrm{a}$ & $49,9 \mathrm{a}$ & $2,30 \mathrm{~b}$ & $70,7 a$ \\
\hline $\mathrm{N}$ & $38,2 \mathrm{a}$ & $12,4 b$ & $49,5 b$ & $3,77 \mathrm{a}$ & $56,7 \mathrm{~b}$ \\
\hline Média puros & 37,7 & $12,7 \mathrm{~B}^{1}$ & $49,7 \mathrm{~A}$ & $3,03 \mathrm{~B}$ & $63,7 \mathrm{~B}$ \\
\hline Straightbreds mean & & & & & \\
\hline $1 / 2 \mathrm{C}+1 / 2 \mathrm{~N}$ & $37,9 c^{3}$ & 12,9 & 49,1 & 3,63 & 68,8 \\
\hline $1 / 2 \mathrm{~N}+1 / 2 \mathrm{C}$ & $37,3 \mathrm{~d}$ & 13,2 & 49,4 & 3,30 & 68,9 \\
\hline Média $F_{1}$ & 37,6 & $13,1 \mathrm{~A}$ & $49,3 \mathrm{~B}$ & $3,46 \mathrm{~A}$ & $68,8 \mathrm{~A}$ \\
\hline $\begin{array}{l}F_{1} \text { mean } \\
\text { Heterose, } \% \\
\text { Heterosis, \% }\end{array}$ & $-0,3\left(\mathrm{NS}^{4}\right)$ & 3,1 & $-0,8$ & 14,2 & 8,0 \\
\hline
\end{tabular}

\footnotetext{
1 A,B, na coluna, na comparação entre puros e $F_{1}$ diferem pelo teste $t(P<0,05)$.

$2 \mathrm{a}, \mathrm{b}$, na coluna, na comparação entre $\mathrm{C}$ e $\mathrm{N}$, diferem pelo teste $\mathrm{t}(\mathrm{P}<0,05)$.

${ }^{3} \mathrm{c}, \mathrm{d}$, na coluna, na comparação entre $1 / 2 \mathrm{C}+1 / 2 \mathrm{~N}$ e $1 / 2 \mathrm{~N}+1 / 2 \mathrm{C}$, diferem pelo teste $\mathrm{t}(\mathrm{P}<0,05)$.

4 Indica heterose não significativa $(P>0,05)$.

$1 A, B$, in the column, for comparison between straigthbreds and $F_{1}$, differ by $t$ test $(P<.05)$.

$2 a, b$, in the column, for comparison between $C$ and $N$, differ by $t$ test $(P<.05)$.

$3 \mathrm{c}, \mathrm{d}$, in the colunn, for comparison between $1 / 2 C+1 / 2 N$ and $1 / 2 N+1 / 2 C$, differ by $t$ test $(P<.05)$.

${ }^{4}$ Non significant heterosis $(P>.05)$.
} 
ças de crescimento pré e pós-desmame possam ter afetado essa característica.

Observa-se na Tabela 3 que os animais $\mathrm{F}_{1}$ apresentaram maior espessura de gordura que os puros, sendo a heterose de $14,2 \%$. Este resultado está de acordo com SLANGER et al. (1985) e URICK et al. (1989), ao comentarem que as características relacionadas à deposição de gordura na carcaça são as que apresentam maiores valores de heterose. Estudando novilhos Aberdeen e Pardo Suiço, MARSHALL et al. (1987) observaram $24,9 \%$ de heterose para a característica marmoreio da carne.

BARBER et al. (1981) estudaram o comportamento da raça $\mathrm{C}$ com respeito ao seu acabamento, em comparação com novilhos de uma raça considerada mais precoce em deposição de gordura (Aberdeen), não verificando diferença no grau de acabamento dos animais, quando se permitiu que o $\mathrm{C}$ atingisse o seu peso adulto. Ao estudarem diferentes pesos de abate para novilhos C, RESTLE et al. (1997a) verificaram que os animais $\mathrm{C}$ atingiram 5,4 $\mathrm{mm}$ de espessura de gordura aos $495 \mathrm{~kg}$, após 184 dias de terminação (RESTLE et al., 1997b).

Observa-se que a área de Longissimus foi maior nos animais cruzados $(\mathrm{P}<0,05)$, com níveis de heterose de $8,0 \%$. Resultados similares aos verificados por BAKER et al. (1984), em animais cruzas Brahman, Aberdeen, Hereford, Holandês e Jersey, e por JOHNSTON et al. (1992), em animais cruza Devon e Hereford. Nos dois trabalhos, a heterose no $F_{1}$ foi de 7,4\% para área de Longissimus. Entretanto, trabalhando com três raças britânicas, OLSON et al. (1978) verificaram níveis de heterose total de 1,3\% para a área de Longissimus. Já NEVILLE JR. et al. (1984) citam heterose negativa para essa característica. Em seus trabalhos, ARNOLD et al. (1990) e MARSHALL (1994) estão de acordo ao afirmarem que nas características de carcaça, quando a idade é fixada como ponto de abate, a heterose é positiva, no entanto passa a ser menos evidente, quando é feito o ajuste para o peso de abate dos animais.

Dentro do SA, DeROUEN et al. (1992a), estudando as raças $\mathrm{C}$, Brahman, Aberdeen e Hereford, concluíram que $\mathrm{C}$ é a raça que possui maior efeito aditivo individual e materno sobre a área de Longissimus.

Estudando as vacas de descarte pertencentes a este projeto, PEROBELLI et al. $(1994,1995)$ citam que a melhor musculosidade da carcaça das vacas $\mathrm{C}$ foi refletida na melhor conformação (Tabela 1), espessura de coxão (Tabela 2) e área de Longissimus (Tabela 3).
É apresentado na Tabela 4 o peso total dos três tecidos principais da carcaça. Observando-se os valores de heterose significativos $(\mathrm{P}<0,05)$ para os pesos de músculo, gordura e osso (apresentados na Tabela 4), verifica-se que assim como a espessura de gordura apresentou alto valor de heterose (Tabela 3), também o peso total de gordura na carcaça foi uma característica com alto nível de heterose $(15,7 \%)$.

Observa-se na Tabela 4 que, na comparação entre os animais puros, o $\mathrm{C}$ apresentou maior peso de músculo e de osso, não diferindo do $\mathrm{N}$ no peso total de gordura $(\mathrm{P}>0,05)$. Maior quantidade de músculo na carcaça de animais $\mathrm{C}$ é citada por PEROBELLI et al. (1995), quando compararam vacas de descarte C e N. Entre os novilhos $F_{1}$, não foi observada diferença significativa em nenhuma das três características mostradas na Tabela 4.

No presente estudo, pode-se verificar que a raça $\mathrm{C}$ apresenta maior velocidade de crescimento que o $\mathrm{N}$, evidenciado pelo maior peso de abate, e se reflete ainda no peso de carcaça, mesmo que o rendimento de carcaça seja superior nos animais Nelore (Tabela 1). Por outro lado, os animais $\mathrm{C}$ aos dois anos de idade apresentam 2,30 $\mathrm{mm}$ de espessura de gordura sobre a carcaça (Tabela 3), valor esse considerado um pouco abaixo dos $3 \mathrm{~mm}$ exigidos pelos frigoríficos.

Tabela 4 - Médias estimadas e heterose para pesos de músculo, gordura e osso na carcaça de novilhos das raças Charolesa e Nelore em cruzamentos recíprocos

Table 4 - Least square means and heterosis for muscle, fat and bone weight of Charolais and Nellore steers in reciprocal crossbreds

\begin{tabular}{lccc}
\hline $\begin{array}{l}\text { Composição } \\
\text { racial } \\
\text { Breed composition }\end{array}$ & $\begin{array}{c}\text { Músculo, } \\
\mathrm{kg} \\
\text { Muscle, } \mathrm{kg}\end{array}$ & $\begin{array}{c}\text { Gordura, } \\
\mathrm{kg} \\
\text { Fat, } \mathrm{kg}\end{array}$ & $\begin{array}{c}\text { Osso, } \\
\mathrm{kg} \\
\text { Bone, } \mathrm{kg}\end{array}$ \\
\hline $\mathrm{C}$ & $164,8 \mathrm{a}$ & 39,4 & $46,4 \mathrm{a}$ \\
$\mathrm{N}$ & $133,7 \mathrm{~b}$ & 40,9 & $40,9 \mathrm{~b}$ \\
Média puros & & & \\
Straightbreds mean & $149,2 \mathrm{~B}$ & $40,2 \mathrm{~B}$ & $43,6 \mathrm{~B}$ \\
$1 / 2 \mathrm{C}+1 / 2 \mathrm{~N}$ & 164,9 & 47,7 & 47,7 \\
$1 / 2 \mathrm{~N}+1 / 2 \mathrm{C}$ & 167,7 & 45,3 & 45,3 \\
Média F & & & \\
$F_{1}$ mean & $166,3 \mathrm{~A}$ & $46,5 \mathrm{~A}$ & $47,3 \mathrm{~A}$ \\
Heterose, $\%$ & & & \\
Heterosis, \% & 11,5 & 15,7 & 8,5 \\
\hline
\end{tabular}

${ }^{1} \mathrm{~A}, \mathrm{~B}$, na coluna, na comparação entre puros e $F_{1}$ diferem pelo teste $t(P<0,05)$.

2 a,b, na coluna, na comparação entre $\mathrm{C}$ e $\mathrm{N}$, diferem pelo teste $\mathrm{t}$ $(P<0,05)$.

${ }_{1} A, B$, in the column, for comparison between straigthbreds and $F_{1}$, differ by $t$ test $(P<.05)$.

$2 a, b$, in the column, for comparison between $C$ and $N$, differ by $t$ test $(P<.05)$. 
O oposto é verificado com o $\mathrm{N}$, uma raça de porte menor, que no presente trabalho apresentou $375 \mathrm{~kg}$ ao abate, mas em relação ao $\mathrm{C}$ mostrou bom grau de acabamento e rendimento de carcaça, esse último característico das raças zebuínas (GALVÃO, 1991). Esse distanciamento genético entre essas duas raças desperta o interesse do produtor no cruzamento entre as mesmas. Os animais $F_{1}$ apresentaram carcaças com peso levemente superior e conformação levemente inferior ao $\mathrm{C}$ e grau de acabamento levemente abaixo do $\mathrm{N}$, mas dentro do que é exigido pelos frigoríficos.

As pequenas diferenças verificadas entre os animais cruzados $1 / 2 \mathrm{C}+1 / 2 \mathrm{~N}$ e $1 / 2 \mathrm{~N}+1 / 2 \mathrm{C}$ também indicam que, partindo de um rebanho de vacas $\mathrm{N}$, pode-se introduzir sêmen ou touro $\mathrm{C}$, sendo que se espera aumento substancial na conformação e no peso de carcaça dos animais.

Este trabalho mostra que, para a atual situação da pecuária de corte, esse cruzamento entre as raças $\mathrm{C}$ e $\mathrm{N}$ é boa alternativa para incrementar a produção de carne, com investimento bastante baixo, que no caso do cruzamento se resume basicamente a gastos com sêmen ou touros.

Os valores de heterose mais altos verificados para as características em que existe maior distanciamento genético entre as raças mostram que, ao planejar o cruzamento em bovinos de corte, deve-se levar em conta as características que devem ser melhoradas e sempre buscar explorar ao máximo o distanciamento genético entre as raças bovinas existentes, desde que estas possam se adaptar às condições de meio da propriedade.

\section{Conclusões}

Novilhos da raça Charolesa apresentaram maiores valores para peso de abate, peso de carcaça fria, conformação, espessura de coxão, área de Longissimus, maiores porcentagens de serrote e de costilhar e maior peso de músculo e osso na carcaça do que novilhos da raça Nelore, sendo que os últimos foram superiores em espessura de gordura e rendimento de carcaça.

Os valores de heterose resultantes do cruzamento entre as raças Charolesa e Nelore foram expressivos para a maioria das características de carcaça.

\section{Referências Bibliográficas}

ALENCAR, M.M., TREMATORE, R.L., OLIVEIRA, J.A.L. et al. 1998. Características de crescimento até a desmama de bovinos da raça Nelore e cruzados Charolês x Nelore. R. Bras. Zootec., 27(1):40-46.

ARNOLD, J.W., BERTRAND, J.K., BENYSHEK, L.L. et al. 1990. Evaluation of carcass composition in four-breed diallel among Simmental, Limousin, Polled Hereford and Brahman beef cattle. J. Anim. Sci., 68(5):1237-44.

ARTHUR, P.F., MAKARECHIAN, M., PRICE, M.A. et al. 1989. Heterosis, maternal and direct effects in double-muscled and normal cattle: II. Carcass traits of young bulls. J. Anim. Sci., 67(4):911-919.

BAKER, J.F., LONG, C.R., CARTWRIGHT, T.C. 1984. Characterization of cattle of a five breed diallel. V. Breed and heterosis effects on carcass merit. J. Anim. Sci., 59(4):922-933.

BARBER, K.A., WILSON, L.L., ZIEGLER, J.H. et al. 1981. Charolais and Angus steers slaughtered at equal percentages of mature cow weight. I. Effects of slaughter weight and energy density on carcass traits. J. Anim. Sci., 52(2):218-231.

DeROUEN, S.M., FRANKE, D.E., BIDNER, T.D. et al. 1992a. Direct and maternal genetic effects for carcass traits in beef cattle. J. Anim. Sci., 70(12):3677-3685.

DeROUEN, S.M., FRANKE, D.E., BIDNER, T.D. et al. 1992b. Two- Three-, and four-breed rotational crossbreeding of beef cattle: carcass traits. J. Anim. Sci., 70(12):3665-76.

FEIJÓ, G.L.D., EUCLIDES FILHO, K., FIGUEIREDO, G.R. et al. Avaliação de carcaças de Nelore e F1's europeu-Nelore a um grau de acabamento constante. In: REUNIÃO ANUAL SOCIEDADE BRASILEIRA DE ZOOTECNIA, 34, 1997, Juiz de Fora. Anais... Juiz de Fora: SBZ, 1997. p.133-135.

FLORES, J.L.C. Desempenho em confinamento e características de carcaça e da carne de bovinos de diferentes grupos genéticos abatidos aos quatorze meses. Santa Maria, RS: UFSM, 1997. 109p. Dissertação (Mestrado em Zootecnia) - Universidade Federal de Santa Maria, 1997.

FRIES, L.A. 1999. Genética de gado de corte orientada para a lucratividade. In: LOBATO, J.F.P., BARCELLOS, J.O.J., KESSLER, A.M. (Eds.) Produção de bovinos de corte, Porto Alegre: EDIPUCRS. p.193-234.

GALVÃ̃O, J.G.C. Estudo da eficiência nutritiva, características e composição física da carcaça de bovinos de três grupos raciais, abatidos em três estágios de maturidade. Viçosa, MG: UFV, 1991. 81p. Dissertação (Mestrado em Zootecnia) - Universidade Federal de Viçosa, 1991.

GONÇALVES, L.C. Digestibilidade, composição corporal, exigências nutricionais e características das carcaças de zebuínos, taurinos e bubalinos. Viçosa, MG: UFV, 1988 , 238p. Tese (Doutorado em Zootecnia) - Universidade Federal de Viçosa, 1988.

HANKINS, O.G., HOWE, P.E. 1946. Estimation of the composition of beef carcasses and cuts. Washington: United States Department of Agriculture (Technical Bulletin, 926).

JOHNSTON, D.J., THOMPSON, J.M., HAMMOND, K. 1992. Additive and nonadditive differences in postweaning growth and carcass characteristics of Devon, Hereford, and reciprocalcross steers. J. Anim. Sci., 70(9):2688-2694. 
KOGER, M. 1980. Effective crossbreeding systems utilizing zebu cattle. J. Anim. Sci., 50(6):1213-20.

LONG, C.R. 1980. Crossbreeding for beef production: experimental results. J. Anim. Sci., 51(6):1197-1206.

MARSHALL, D.M. 1994. Breed differences and genetic parameters for body composition traits in beef cattle. J. Anim. Sci., 72(10):2745-2755.

MARSHALL, T.T., HARGROVE, D.D., OLSON, T.A. 1987. Heterosis and additive breed effects on feedlot and carcass traits from crossing Angus and Brown Swiss. J. Anim. Sci., 64(5):1332-1339.

MOLETTA, J.L., RESTLE, J. 1996. Características de carcaça de novilhos de diferentes grupos genéticos terminados em confinamento. R. Soc. Bras. Zootec., 25(5):876-888.

MULLER, L. 1987. Normas para avaliação de carcaças e concurso de carcaça de novilhos. 2.ed. Santa Maria: UFSM. 31p.

NEVILLE JR., W.E., MULLINIX JR., B.G., McCORMICK, W.C. 1984. Grading and rotational crossbreeding of beef cattle. III. Postweaning and carcass traits of steers. J. Anim. Sci., 58(1):47-56.

OLSON, L.W., CUNDIFF, L.V., GREGORY, K.E. 1978. Maternal heterosis effects on postweaning growth and carcass traits in beef cattle. J. Anim. Sci., 46(6):1552-1562.

PEROBELLI, Z.V., MULLER, L., RESTLE, J. 1994. Estudo da qualidade das carcaças e da carne de vacas de descarte de dois grupos genéticos. Ciência Rural, 24(3):613-616.

PEROBELLI, Z.V., RESTLE, J., MULLER, L. 1995. Estudo das carcaças de vacas de descarte das raças Charolês e Nelore. Pesq. Agrop. Bras., 30(3):409-412.

PEROTTO, D., CUBAS, A.C., MOLETTA, J.L. et al. 1998. Pesos ao nascimento e à desmama e ganho de peso do nascimento à desmama de bovinos Charolês, Caracu e cruzamentos recíprocos. R. Bras. Zootec., 27(4):730-737.

PRESTON, T.R., WILLIS, M.B. 1970. Intensive beef production. Oxford: Pergamon Press. 544p.

RESTLE, J., FELTEN, H.G., VAZ, F.N. Efeito de raça e heterose para características quantitativas da carcaça de novilhos de 24 meses terminados em confinamento. In: REUNIÓN LATINOAMERICANA DE PRODUCCIÓN ANIMAL, 14, 1995, Mar del Plata. Memorias... Balcarce: ALPA, 1995a. p.857-859.

RESTLE, J., FELTEN, H.G., VAZ, F.N. Efeito de raça e heterose para desempenho em confinamento de novilhos de corte. In: REUNIÓN LATINOAMERICANA DE PRODUCCIÓN ANIMAL, 14., 1995, Mar del Plata. Memorias... Balcarce: ALPA, 1995b. p.852-854.
RESTLE, J., KEPLIN, L.A.S., VAZ, F.N. 1997a. Características quantitativas da carcaça de novilhos Charolês, abatidos com diferentes pesos. Pesq. Agrop. Bras., 32(8):851-856.

RESTLE, J., KEPLIN, L.A.S., VAZ, F.N. 1997b. Desempenho em confinamento de novilhos Charolês terminados com diferentes pesos. Pesq. Agrop. Bras., 32(8):857-860.

RESTLE, J., KEPLIN, L.A.S., VAZ, F.N. et al. 1996. Qualidade da carne de novilhos Charolês confinados e abatidos com diferentes pesos. Ciência Rural, 26(3):463-466.

RESTLE, J., VAZ, F.N. 1999. Confinamento de bovinos puros e cruzados. In: LOBATO, J.F.P., BARCELLOS, J.O.J., KESSLER, A.M. (Eds.) Produção de bovinos de corte, Porto Alegre: EDIPUCRS. p.141-168.

RESTLE, J., VAZ, F.N., QUADROS, A.R.B. et al. 1999. Características de carcaça e da carne de novilhos de diferentes genótipos Hereford x Nelore. Rev. bras. zootec., 28(6):1245-1251.

SAS, Institute Inc. 1990. SAS Language reference. Version 6, Cary, NC: SAS Institute Inc. 1042p.

SLANGER, W.D., MARCHELLO, M.J., DANIELSON, R.B. et al. 1985. Muscle tenderness, other carcass traits and the effect of crossbreeding on these traits in beef cattle. J. Anim. Sci., 61(6):1402-1410.

URICK, J.J., PAHNISH, O.F., KNAPP, B.W. 1989. Comparison of two- and three-way rotational crossing, beef $\mathrm{x}$ beef and beef $\mathrm{x}$ Brown Swiss composite breed production: postweaning growth and carcass traits. J. Anim. Sci., 67(10):2603-2618.

WHEELER, T.L., CUNDIFF, L.V., KOCH, R.M. 1996. Characterization of biological types of cattle (Cycle IV): carcass traits and longissimus palatability. J. Anim. Sci., 74(5):1023-1035.

Recebido em: 27/04/00

Aceito em: 03/09/00 